\title{
Criss-cross heart
}

INSERM

\section{Source}

INSERM. (1999). Orphanet: an online rare disease and orphan drug data base. Criss-crosS heart. ORPHA:1461

Criss cross heart ( $\mathrm{CCH}$ ) is a cardiac malformation where the inflow streams of the two ventricles cross due to twisting of the heart about its major axis. The clinical features depend on the particular cardiac defects associated, like simple or corrected transposition of the great arteries and ventricular septal defects. 